\title{
Siblings with Autism, Mental Retardation, and Convulsions in Tuberous Sclerosis: A Case Report
}

\author{
Farihan Farouk Helmy ${ }^{1 *}$, Adnan Amin Alsulaimani ${ }^{1}$, Amal Abdulrahman Hunjur ${ }^{2}$, \\ Shahad Sati Alheraiti ${ }^{2}$ \\ ${ }^{1}$ Pediatric Department, College of Medicine, Taif University, Taif, Saudi Arabia \\ ${ }^{2}$ College of Medicine, Taif University, Taif, Saudi Arabia \\ Email: *Farihanhelmy@gmil.com,adnamn@gmail.com, a.hanjour@gmail.com,dr.shahad92@gmail.com
}

Received 23 March 2016; accepted 23 July 2016; published 26 July 2016

Copyright (C) 2016 by authors and Scientific Research Publishing Inc.

This work is licensed under the Creative Commons Attribution International License (CC BY).

http://creativecommons.org/licenses/by/4.0/

(c) (i) Open Access

\section{Abstract}

A 3-year-old female patient born of consanguineous parents presented to the (development and behavioral clinic) in Taif children hospital, Western Saudai Arabia, her mother complained that her daughter had speech delay, no eye to eye contact, and was performing stereotyped behaviors (hand flapping). The girl developed convulsions at the age of 3 months and was on anticonvulsant medication since that age; her convulsions were controlled on anti-epileptic treatment. Family history revealed that the girl had a 6-year-old male sibling who developed convulsions at the age of 4 months and is on antiepileptic medications; the boy suffered also from speech delay, absent social interaction, and repetitive behaviors. On examination the girl had characteristic features of angio-fibromas, hypo-pigmented macules on the trunk and legs, and moreover the boy had similar skin features plus hypo-pigmented tufts of hair. Both cases were diagnosed as Autistic spectrum disorder, tuberous sclerosis, and mental retardation. The family needed genetic counseling, while both cases needed as soon as possible behavioral and educational strategies.

\section{Keywords}

Autism, Menatl Retardation, Tuberous Sclerosis, Children

\section{Introduction}

Autism spectrum disorder (ASD) is a neurodevelopmental disorder characterized by impaired social interaction, verbal and non-verbal communication, and restricted and repetitive behavior [1].

\footnotetext{
*Corresponding author.
}

How to cite this paper: Helmy, F.F., Alsulaimani, A.A., Hunjur, A.A. and Alheraiti, S.S. (2016) Siblings with Autism, Mental Retardation, and Convulsions in Tuberous Sclerosis: A Case Report. World Journal of Neuroscience, 6, 220-226. 
The number of children known to have autism has increased dramatically world-wide since the 1980s [2], with an average of 4.3:1 male-to-female ratio [3]. Estimates for ASD prevalence in Saudi Arabia are not available in the literature [4]; however a study conducted by Zahrani 2013 [5] found that the overall prevalence of autism in the primary school in Taif KSA whose age ranged from 7 to 12 years was $0.035 \%$.

The recurrence rate in siblings of affected children with ASD is approximately $2 \%$ to $8 \%$, much higher than the prevalence rate in the general population but much lower than in single-gene diseases [6].

According to twin studies, there is $60 \%$ concordance for classic autism in monozygotic (MZ) twins versus 0 in dizygotic (DZ) twins; the higher MZ concordance is in preference to genetic inheritance as the predominant causative agent [7]. There is increase in concordance rate remarkably from $60 \%$ to $92 \%$ in $\mathrm{MZ}$ twins and from $0 \%$ to $10 \%$ in DZ pairs, in cases of broader autistic phenotype that includes communication and social disorders [8] suggesting that interactions between multiple genes cause "idiopathic" autism but that epigenetic factors and exposure to environmental modifiers may contribute to variable expression of autism-related traits [9].

Tuberous sclerosis is a rare genetic disorder; its incidence is 1 in 6000 to 1 in 10,000 live births with no ethnic clustering [10]. It is an autosomal dominant disease; approximately two thirds of cases are sporadic with no family history of the disease. The disease is characterized by non-cancerous tumors throughout the brain and body [11].

The co-occurrence of autism spectrum disorder and tuberous sclerosis complex has been recognized since long time. It was found that prevalence of tuberous sclerosis complex in the autism spectrum disorder population is $1 \%$ to $4 \%$, whereas features of autism spectrum disorder are present in $25 \%$ to $50 \%$ of individuals with tuberous sclerosis complex [12]. The mechanism underlying the association of autism and TSC is as yet unclear but clinical features and neuroimaging investigations suggest that an abnormal TSC gene may directly influence the development of autism rather than it being a secondary effect of seizures or MR. The presence of autism/PDD may arise if the TSC gene mutations occur at critical stages of neural development in neural tissue of brain regions critical in the development of autism [13].

\section{Case Presentation}

A female child 3 years old, born of a consanguineous marriage from a middle class family living in Mecca, Saudia Arabia was brought by her mother to (developmental and behavioral clinic) in Taif Children’s Hospital with a history of delayed speech, echolalia, fails to respond when people speak to her, and she had repetitive behaviors in the form of continuous hand flapping. Mother noticed these manifestations since her daughter was about 2 years old, she saught medical advice from private doctor who insured her that her daughter is within normal for her age. According to the mother the peri-natal history was unremarkable, with normal vaginal delivery and no history of nursery admission. At age of 3 months the girl developed tonic-clonic convulsions, diagnosed as epilepsy and is controlled ant-epileptic medication Levetiracetam (Keppra) $3 \mathrm{mg} / \mathrm{kg}$ BID and Valproic acid (Depakene) $1.5 \mathrm{mg} / \mathrm{kg}$ BID. While the girl walked at age 2 years, mother noticed delay in speech, cognitive and social areas of development. In relation to family history her father was epileptic, controlled on Tegretol (Carbamazepine) $200 \mathrm{mg}$ BID, with facial angiofibromas, though he refused examination he denied any skin lessions or hypo-pigmentations. The family had a 6 years old boy, who also developed convulsions at the age 4 months and was controlled on anti-epileptic medications Levetiracetam (Keppra) 4 mg/kg BID, Valproic acid (Depakene) $3 \mathrm{mg} / \mathrm{kg}$ BID and Lamotrigine (Lamictal) $25 \mathrm{mg}$ BID. The mother noticed that boy had the same language, social and behavioral abnormalities like his sister, moreover he had hypopigmented tufts of hair, MRI was requested for the boy but the mother did not follow. We asked mother to bring the boy for examination and evaluation of both cases.

\section{On Examination}

The girl was found hyperactive, not interested in the surroundings, with no eye to eye contact expressionless, with repetitive running in circle movements, and hand flapping, mother complained that the girl was aggressive with her brother. Her body built was within average weight $12.6 \mathrm{Kg}$ on $25^{\text {th }}$ percentile for age, height $94 \mathrm{~cm}$ on $50^{\text {th }}$ percentile for age and head circumference $49 \mathrm{~cm}$ on $50^{\text {th }}$ percentile for age. There were hypo-pigmented lesions on both legs and back (Figure 1).

She had low IQ, moreover showed higher function disturbance, ex (orientation in time and place). She had 


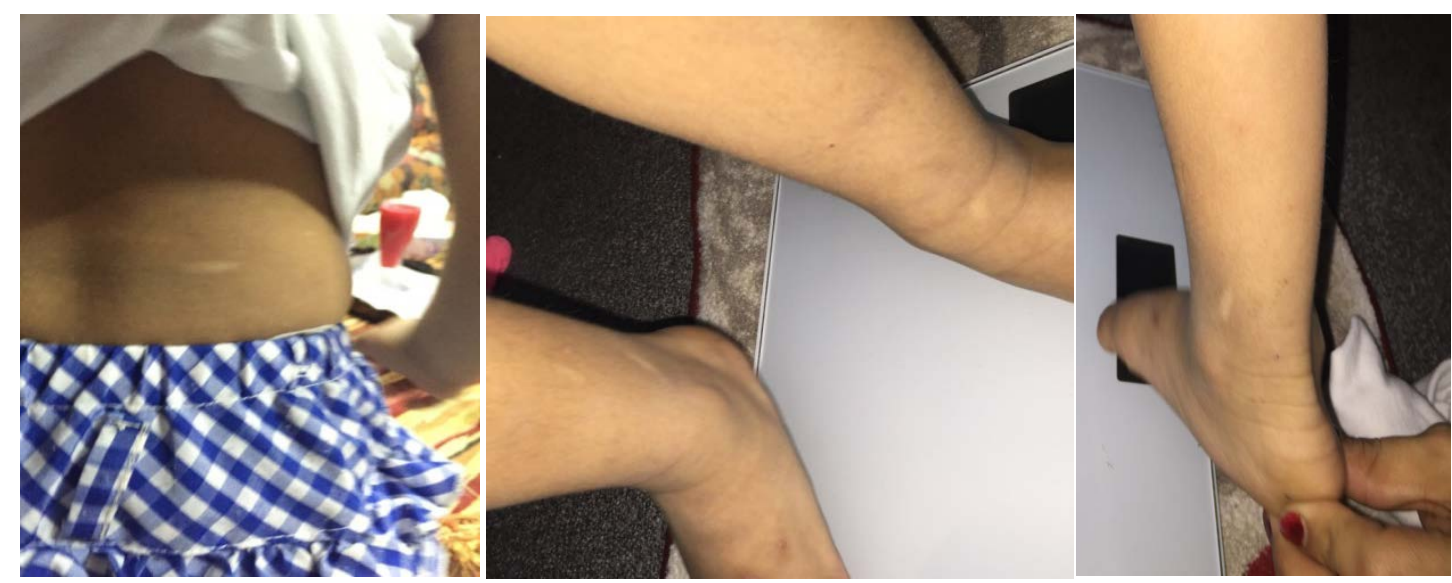

Figure 1. Female patient showing hpo-pigmented patched on back and both lower limbs.

delayed speech (only saying one word), with normal cranial nerves and motor functions. Other neurological and systemic examination appeared normal. Psychiatric assessment with Stanford-Benet test [14] and CARS autism Rating Scale (15) revealed the child was suffering from moderate to severe autism and moderate mental retardation with IQ score 30 - 40.

CT scan of the brain (Figure 2) showed candle-dripping appearances (multiple foci of Subependymal calcification); they were also present in both basal ganglia, both temporal and left parietal regions.

As for the boy he was hyperactive, lacked eye contact, was repeatedly running purposelessly around the room continuously hand clapping. He had an average body built, weight $17.5 \mathrm{~kg}$ on $10^{\text {th }}$ percentile for age, height 104 $\mathrm{cm}$ on $5^{\text {th }}$ percentile for age and head circumference $50 \mathrm{~cm}$ on $25^{\text {th }}$ percentile for age. Developmentally, he had normal motor development while he was delayed in both speech (saying only 2 words) and cognitive areas.

CARS Autism Rating Scale [15] and Stanford Benet test [14] revealed the child was suffering from moderate to severe autism along with severe mental retardation, intelligent score was about 25 to 30 .

While his face showed facial angio-fibromatosis with butterfly distribution covering nose and spreading to cheeks. His skin examination revealed hypo-pigmented patches over the trunk and legs, with hypo-pigmented tuft of hair (Figure 3). Brain non contrast T2-weighted magnetic resonance image for the boy showed extensive high-signal cortical lesions typical of tuberous sclerosis (Figure 4).

Regarding ultrasonography of kidneys and liver for both cases showed no abnormality, echocardiography of heart revealed no rhabdomyoma of cardiac muscle. Opthalmolscopic examination was also normal.

Both patients were diagnosed as Tuberous sclerosis with autistic spectrum disorder. The family was instructed for genetic counseling, the children were sent for psychotherapy, and speech therapy

\section{Discussion}

Autism spectrum disorder (ASD) refers to a group of complex neurodevelopment disorders characterized by repetitive and characteristic patterns of behavior and difficulties with social communication and interaction. The symptoms are present from early childhood and affect daily functioning [16]. It has a genetic influences indicated from twin and family studies and from the co-occurrence of autism with known genetic disorders, such as fragile $\mathrm{x}$ and tuberous sclerosis [8].

Diagnostic criteria of autism spectrum disorder, according to DSM Criteria [17] (Table 1).

Tuberous sclerosis complex (TSC) is a known genetic disorder with behavioral manifestations including autism [11]. It is a rare disease which causes cells to grow beyond the stopping criterion of their development [12]. The most frequently observed manifestations are those of the skin and of the central nervous system like seizures, mental retardation, followed by renal, cardiac and ocular manifestations. Among cutaneous manifestations, hypomelanotic macules, facial angiofibromas, shagreen spots, fibrous plaques on the forehead and ungula fibroma are observed. A definitive diagnosis of TSC requires that a patient present with two of the major criteria shown in Table 2 or one major and two minor criteria [18].

A literature review of these two disorders substantiates a significant association of autism and (TSC) with $17 \%-58 \%$ of TSC subjects manifesting autism and $0.4 \%$ - 3\% of autistic subjects having TSC [19]. 


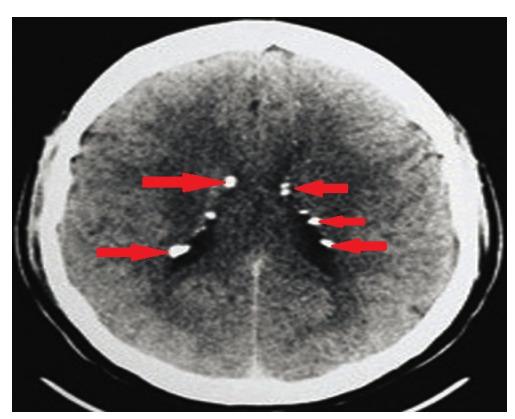

Figure 2. CT Brain of a 3 y old female revealing calcified lesions/sub-ependymal hamartomas seen along the lateral surface of the lateral ventricles giving rise to characteristic candle dripping appearance.

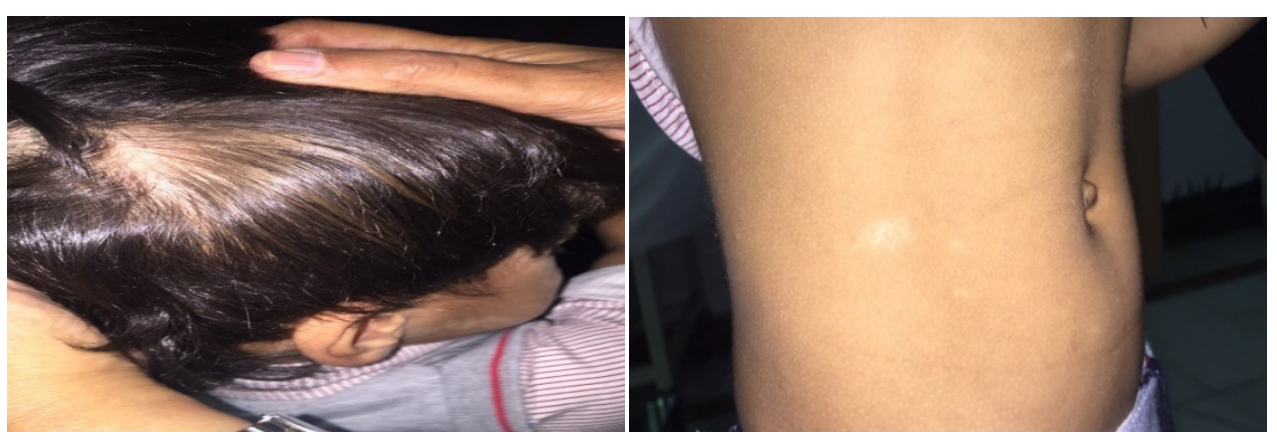

Figure 3. Male patient 6 y old showing cutaneous features of tuberous sclerosis including hypomelanotic macule, and hypo-pigmented patches on the trunk.

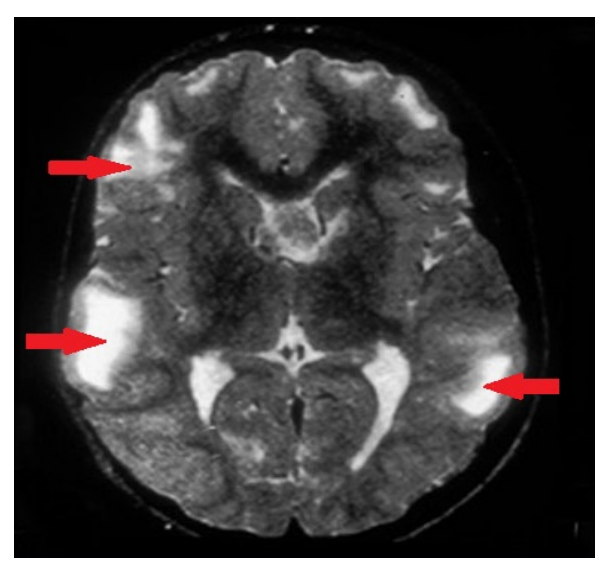

Figure 4. Brain Non contrast T2-weighted magnetic resonance image for 6 y old boy, demonstrates extensive high-signal cortical lesions.

Both our patients showed skin manifestations in the form of hypomelanotic macules present in large number on the front and back of the trunk, legs, facial angiofibromas lesions were present on the face over nose and malar region in butterfly distribution, hyper pigmented patches on left upper forehead and right cheek were present.

Brain changes for the girl was in the form of tubers throughout the cortex and mostly insubependymal regions giving rise to candle-dripping appearance, while for the boy MRI brain showed extensive high-signal cortical lesions typical of tuberous sclerosis. Sometimes the tuber converts to giant cell astrocytoma which may block the foramen of Monro resulting in hydrocephalus [20]. Due to cortical tubers the convulsion is a most common and early feature of this disease. Any type of convulsion from infantile spasm, myoclonic convulsion to persistent tonic convulsion may occur [21]. Both our patients had early onset convulsions, while the girl developed tonicclonic convulsions at the age three months, the boy also developed convulsion at the age of four months and 
Table 1. DSM-5 diagnostic criteria for autism spectrum disorder (ASD) 1.

Diagnostic Criteria for Autism Spectrum Disorder (ASD)

Severity is based on social communication impairments and restricted, repetitive patterns of behavior

A) Persistent deficits in social communication and social interaction across multiple contexts

B) Restricted, repetitive patterns of behavior, interests, or activities

C) Symptoms must be present in the early developmental period (may be masked by learned strategies in later life).

D) Symptoms cause clinically significant impairment in social, occupational, or other important areas of current functioning.

E) These disturbances are not better explained by intellectual disability (intellectual developmental disorder) or global developmental delay.

Specified further:

- With or without accompanying intellectual impairment

- With or without accompanying language impairment

- $\quad$ Associated with a known medical or genetic condition or environmental factor

- With catatonia

Table 2. Diagnostic criteria for tuberous sclerosis complex Major features.

\begin{tabular}{cc}
\hline Major Features & Minor Features \\
\hline Facial angiofibromas or forehead plaque & Multiple randomly distributed pits in dental enamel \\
Nontraumatic ungual or periungual fibroma & Hamartomatous rectal polyps \\
Hypomelanotic macules (more than three) & Bone cysts \\
Shagreen patch (connective tissue nevus) & Cortical tuber \\
Subependymal nodule & Cerebral white-matter "migration tracts” \\
Gingival fibromas \\
Subependymal giant cell astrocytoma & Nonrenal hamartoma \\
Multiple retinal nodular hamartomas Cardiac rhabdomyoma & Retinal achromic patch \\
Lymphangiomyomatosis & "Confetti" skin lesions \\
Renal angiomyolipoma & Multiple renal cysts \\
\hline
\end{tabular}

admitted this time with severe intractable convulsion. Convulsions were controlled in both cases on anti-epileptic medications.

Other systems like ocular manifestations of hypo-pigmented macule on iris, retinal phakomas and renal angiomyolipomas are more common in older age group. Cardiac rhabdomyomas may present in almost of half of the pediatric cases [18].

Systematic evaluation of neuropsychological attention skills in a population-derived sample of children and adolescents with TSC showed that, even when age, gender, IQ, and intra-familial clustering were controlled for, the TSC group had significantly lower scores than their unaffected siblings on a range of neuropsychological attentional tasks, and that they had significantly more neuropsychological attention deficits [22]. The findings suggest that clinical neuropsychological evaluation of attentional skills should be performed in children and adolescents with TSC [23].

Treatment of TSC is symptomatic, Rapamycin is still an experimental drug. If anticonvulsant medications and dietary modifications are not effective, then neurosurgical intervention can be considered in selective cases [24]. Anticonvulsants for seizures, shunting for hydrocephalus, and behavioral and educational strategies for mental retardation are the mainstays of management [21]. The mainstay of seizure control for patients with TS is medical therapy with anticonvulsant drugs and a ketogenicdiet [25]. In both our cases although Vigabatrin was not used for seizures control evidence is accumulating that vigabatrin, an inhibitor of $\gamma$-aminobutyric acid transaminase, is the anticonvulsant medication of choice for patients with TSC [26].

\section{Conclusions}

In our case bringing the girl to (development and behavior clinic) with abnormal behavior and delayed development helped finding the fulfillment of the diagnostic criteria of TSC for both siblings.

A fruitful approach for delineating genetic influences in autism may come from further investigation of possible mechanisms underlying the association of autism and TSC.

Along with the treatment with anticonvulsive drugs regular counseling as early as possible should be done 
along with behavioral and educational strategies for mental retardation.

\section{References}

[1] American Psychiatric Association (2000) Diagnostic and Statistical Manual of Mental Disorders. 4th Edition, Text Revision. APA, Washington (DC).

[2] Rutter, M. (2005) Incidence of Autism Spectrum Disorders: Changes over Time and Their Meaning. Acta Paediatrica, 94, 2-15. http://dx.doi.org/10.1080/08035250410023124

[3] Newschaffer, C.J., Croen, L.A., Daniels, J., et al. (2007) The Epidemiology of Autism Spectrum Disorders. Annual Review of Public Health, 28, 235-258. http://dx.doi.org/10.1146/annurev.publhealth.28.021406.144007

[4] Al-Salehi, S.M., Al-Hifthy, E.H. and Ghaziuddin, M. (2009) Autism in Saudi Arabia: Presentation, Clinical Correlates and Comorbidity. Transcult Psychiatry, 46, 340-347. http://dx.doi.org/10.1177/1363461509105823

[5] Al-Zahrani, A. (2013) Prevalence and Clinical Characteristics of Autism Spectrum Disorders in School-Age Children in Taif-KSA. International Journal of Medical Science and Public Health, 2, 578-582.

[6] Boyle, C.A., Boulet, S., Schieve, L., Cohen, R.A., Blumberg, S.J., et al. (2011) Trends in the Prevalence of Developmental Disabilities in US Children, 1997-2008. Pediatrics, 127, 1034-1042. http://dx.doi.org/10.1542/peds.2010-2989

[7] Freitag, C.M. (2007) The Genetics of Autistic Disorders and Its Clinical Relevance: A Review of the Literature. Molecular Psychiatry, 12, 2-22. http://dx.doi.org/10.1038/sj.mp.4001896

[8] Muhle, R., Trentacoste, S. and Rapin, I. (2004) The Genetics of Autism. Pediatrics, 113, 472-486.

[9] Stokstad, E. (2001) Development. New Hints into the Biological Basis of Autism. Science, 294, 34-37. http://dx.doi.org/10.1126/science.294.5540.34

[10] Finkelstein, R. (2004) Advances in Tuberous Sclerosis Complex Research: The October 1, 2003, Child Neurology Society Work Shop. Journal of Child Neurology, 19, 734-735.

[11] AU, K., Williams, A., Gambello, M. and Northrup, H. (2004) Molecular Genetic Basis of Tuberous Sclerosis Complex: From Bench to Bedside. Journal of Child Neurology, 19, 699-709.

[12] Wiznitzer, M. (2004) Autism and Tuberous Sclerosis. Journal of Child Neurology, 19, 675-679.

[13] Smalley, S. (1998) Autism and Tuberous Sclerosis. Journal of Autism and Developmental Disorders, 28, 407-714.

[14] Roid, G.H. (2003) Stanford-Binet Intelligence Scales. 5. Riverside Publishing, Rolling Meadows.

[15] Schopler, E., Reichler, R. and Rochen Renner, B. (1988) The Childhood Autism Rating Scale. Western Psychological Services.

[16] Rutter, M. and Schopler, E. (1987) Autism and Pervasive Developmental Disorders: Concepts and Diagnostic Issues. Journal of Autism and Developmental Disorders, 17, 159-186. http://dx.doi.org/10.1007/BF01495054

[17] American Psychiatric Association (2013) Diagnostic and Statistical Manual of Mental Disorders. 5th Edition, American Psychiatric Association, Arlington.

[18] Söğüt, A., Ozmen, M., Sencer, S., Calişkan, M., et al. (2002) Clinical Features of Tuberous Sclerosis Cases. The Turkish Journal of Pediatrics, 44, 98-101.

[19] Smalley, S., Tanguay, P., Smith, M. and Gutierrez, G. (1992) Autism and Tuberous Sclerosis. Journal of Autism and Developmental Disorders, 22, 339-355. http://dx.doi.org/10.1007/BF01048239

[20] Ridler, K., Suckling, J., Higgins, N., Bolton, P. and Bullmore, E. (2004) Standardized Whole Brain Mapping of Tubers and Subependymal Nodules in Tuberous Sclerosis Complex. Journal of Child Neurology, 19, 658-665.

[21] Thiele, A. (2004) Managing Epilepsy in Tuberous Sclerosis Complex. Journal of Child Neurology, 19, 680-686.

[22] de Vries, P., Gardiner, J. and Bolton, P. (2009) Neuropsychological Attention Deficits in Tuberous Sclerosis Complex (TSC). American Journal of Medical Genetics Part A, 149A, 387-395. http://dx.doi.org/10.1002/ajmg.a.32690

[23] Anderson, V., Fenwick, T., Manly, T. and Robertson, I. (1998). Attentional Skills Following Traumatic Brain Injury in Childhood: A Componential Analysis. Brain Injury, 12, 937-949. http://dx.doi.org/10.1080/026990598121990

[24] Maria, B., Deidrick, K., Roach, S., David, H. and Gutmann, D. (2004) Tuberous Sclerosis Complex: Pathogenesis, Diagnosis, Strategies, Therapies, and Future Research Directions. Journal of Child Neurology, 19, 632-642.

[25] Thiele, E.A. (2003) Assessing the Efficacy of Antiepileptic Treatments: The Ketogenic Diet. Epilepsia, 44, 26-29. http://dx.doi.org/10.1046/j.1528-1157.44.s7.4.x

[26] Hancock, E. and Osborne, J.P. (1999) Vigabatrin in the Treatment of Infantile Spasms in Tuberous Sclerosis: Literature Review. Journal of Child Neurology, 14, 71-74. http://dx.doi.org/10.1177/088307389901400201 


\section{Abbreviations}

CARS: Childhood Autism Rating Scale;

CNS: Central Nervous System;

CT: Computed Tomography;

TSC: Tuberous Sclerosis Complex.

\section{Submit or recommend next manuscript to SCIRP and we will provide best service for you:}

Accepting pre-submission inquiries through Email, Facebook, LinkedIn, Twitter, etc.

A wide selection of journals (inclusive of 9 subjects, more than 200 journals)

Providing 24-hour high-quality service

User-friendly online submission system

Fair and swift peer-review system

Efficient typesetting and proofreading procedure

Display of the result of downloads and visits, as well as the number of cited articles

Maximum dissemination of your research work

Submit your manuscript at: http://papersubmission.scirp.org/ 